\title{
Fathers of people with an intellectual disability: a review of the literature
}

\begin{abstract}
:
The aim of this paper is to review the literature related to fathers of people who have an intellectual disability. Electronic databases and citation tracking were used to collate data using key terms such as fathers, adults with an intellectual disability, learning disability, mental handicap and developmental disability. Relevant articles were analysed and compared for commonality and difference.
\end{abstract}

Eight themes emerged from the literature: response to diagnosis; varied response to intellectual disability; concern for the future; work; roles and relationships; impact of fathers upon child development; fathers and service providers; fathers' needs and coping strategies.

This review of the literature presents areas of similarity and divergence, and highlights the lack of information that relates specifically to fathers of adults. There are clear messages to service providers to support the inclusion of fathers and the need for further research in this area is indicated.

\section{Introduction}

There is very little available research that reports solely upon the fathers of adults who have an intellectual disability. This paper provides a review of the current research and represents fathers of people who have an intellectual disability from birth up to the age of 22 . Eight themes within the literature are discussed: response to diagnosis; varied response to intellectual disability; concern for the future; work; roles and relationships; impact of fathers upon child development; fathers and service providers; fathers' needs and coping strategies. These themes are followed by a discussion on areas of commonality and difference between the findings presented, alongside recommendations for service providers who are likely to encounter fathers of people with intellectual disability. 


\section{Background}

There is now a general cultural expectation within the UK that fathers will be involved in the care and support of their children at both a practical and financial level (O`Brien 2005; Towers 2007) and certain studies report upon the unique contribution that fathers can make to the cognitive and social development of their offspring (Meyer et al 1982; Gallagher et al 1981; Flippin and Crais 2011). Furthermore, fathers who are actively involved with their children in the early years are more likely to remain involved over the life cycle (Meyer et al 1982; Flippin and Crais 2011).

Despite this reference to fathers, much research that relates to the parents of children and adults who have an intellectual disability tends to focus upon mothers (Quinn 1999; Meyer et al 1982; Rendall 1997; Davis and May 1991). There is a dearth of research about fathers of adults within this field (Gore 2010) despite it being claimed that mothers are better able to perform their care role when fathers are involved (Meyer et al 1982; Flippin and Crais 2011) and that fathers form an integral part of the family support system (Flippin and Crais 2011).

Overall, the needs and wishes of fathers of people who have an intellectual disability have received less attention in the literature than mothers (Meyer et al 1982; West 2000) yet the demands being placed upon families are increasing due to longevity, reduced resources and budgetary constraint (Mclnnes et al 2011; Bertelli et al 2011; Taylor and Hodapp 2012). The Foundation for People with Learning Disabilities (Towers and Swift 2006) noted that three quarters of their sample of 21 fathers reported stress in relation to their parental role and some referred to difficulty with their physical health. Specific concerns reported by the Foundation included the future care needs of their child and employment issues, such as trying to manage a balance between home and work, and the difficulty in attending meetings about their child. A national study of 250 fathers undertaken by the Foundation (Towers, 2009) reported a lack of both practical and emotional support from the wider family, difficulty spending 
time with their children due to work constraints and difficulty in having their role recognised by service providers. Similar issues were raised in a systematic review by Flippin and Crais (2011). While specific to Autistic Spectrum Disorder, it highlighted the need for fathers to engage with their children, for support for fathers with their mental wellbeing and for education on how to best support their child, alongside consideration of their significance in the family support system over the duration of the life course.

A literature review related to father involvement in the presence of disability (Quinn 1999) found that in general terms, father involvement was linked to increased child cognitive competence and enhanced social skills, however barriers to father involvement included social roles and expectation, lack of experience and knowledge of child development, reduced support networks and workplace issues. With specific reference to fathers of children with a disability, themes highlighted by Quinn (1999) include initial reaction to diagnosis, adaptation to the disability, difficulties with professionals, care related stress, concern for the future, mixed response to disability and the presence of personal growth. Themes of distress and anger, loss and bereavement when a child is diagnosed as having an intellectual disability were raised by Davis and May (1991) who from a personal perspective claim that fathers in this situation have difficulty in expressing their grief due to social role expectations, yet nevertheless state that fathers need to grieve for their sense of loss, to have support, and actively engage in their child's life. In light of this background therefore, the role of fathers is an important area to consider

\section{Aim}

The aim of this paper is to review the literature that relates to fathers of people who have intellectual disability and to provide a foundation to future research within this field. 


\section{Method}

An initial search was conducted between October 2014 and May 2015 using the key terms of fathers, adults with an intellectual disability, learning disability, mental handicap and developmental disability. The following databases were used; OVID, AMED, CINAHL, Psychinfo and Google Scholar. A total of 43 papers were identified which had been published between 1976 and 2014.Abstracts were then read by all three researchers to ensure that the papers concerned intellectual disability; this reduced the number to 23 .

Between March and May 2015 hand searching then took place to identify studies that were reported in the 23 papers and a further 5 were identified. Papers were then read by at least two of the researchers and a further sifting took place based on the following inclusion and exclusion criteria, which resulted in a total of 27 papers being included within the review.

Inclusion criteria were that articles presented primary research and were published in peer reviewed journals from 1976 onwards. Only articles that provided a significant emphasis upon fathers, specifically referred to children with an intellectual disability and provided clear detail of the aim, method of data collection and analysis were included. Some studies included children with intellectual disability and those with physical disability. Articles were excluded if they were not based on primary research. When articles met the inclusion criteria, they were read through again and critically reviewed by at least two members of the review team. Notes were made upon the aim of the research article, the sample size, method of data collection, method of analysis, results and key results (Table 1). In addition, a critical summary of each article was formulated to aid the review process. The results from each article were then considered by the review team and 8 emergent themes were generated from the research findings.

\section{Results}


In total, 8 overarching themes were identified as arising from the results of the included papers: response to diagnosis; varied response to intellectual disability; concern for the future; work; roles and relationships; impact of fathers upon child development; fathers and service providers; fathers' needs and coping strategies.

\section{Response to diagnosis:}

Hornby (1992) presented a review of 8 personal accounts by fathers of children who have an intellectual disability. Although this small scale study reported upon personal experiences and lacked detail such as participant ages, socioeconomic status or data analysis, accounts were longitudinal and reported high levels of emotional intensity, shock, distress, fear and altered expectations as a common response to diagnosis. A further paper by Hornby (1995a) undertook semi-structured interviews with 90 UK fathers of children who have Down syndrome. $42 \%$ noted initial difficulty in adjusting to the diagnosis and the adjustment period varied from brief to enduring. An exploration of the meaning of fatherhood in the US study by Baumann and Braddick (1999) reported the same initial response of shock and distress to diagnosis. These themes are present again in the Swedish qualitative longitudinal study by Bostrom and Broberg (2014) and emerge further in studies by Rivard and Mastel-Smith (2013) from their interviews with 6 fathers of children who were diagnosed with a genetic disorder, and small scale studies by West (1998) and Herbert and Carpenter (1994), both of who interviewed small numbers of fathers of children with Down syndrome.

Despite common reports of distress, shock and upset at diagnosis, many articles refer to paternal adjustment and adaptation over time (Hornby 1992; Bostrom and Broberg 2014; Rivard and MastelSmith 2013 and Baumann and Braddick 1999). Vadasay et al (1986) in their follow up evaluation of a programme offered to fathers of children with a disability in the US note a significant decrease in depression and reduced levels of grief and stress over time. Carpenter and Towers' (2008) UK study, 
which utilised semi-structured interviews with 21 fathers of children with intellectual disability notes difficulty in receiving the diagnosis, however like Hornby's study (1995a) most fathers reported adaptation. The small scale New Zealand study by Bray et al (1995) that considered the experience and needs of 15 fathers of children who had disabilities aged between 2- 13 years, reiterated distress at diagnosis but also identifies adaptation and acceptance over time. In further reference to paternal adaptation, Hornby (1995b) utilised questionnaires and measures related to adaptation, marital satisfaction, social support, stress levels and personality with 87 UK fathers of children with Down syndrome. This study demonstrated that paternal adaptation was associated with perceived satisfaction with social support and their marital relationship and with particular personality traits, rather than the characteristics of the child who had a disability.

\section{Varied response to intellectual disability}

The representation of stress for fathers of children who have an intellectual disability is diverse within the literature and a number of comparative studies have been undertaken. A US study by Cummings (1976) reported the findings of self-administered tests on 60 fathers of children with an intellectual disability, 60 whose child had a long term physical health condition and 60 whose children were typically developing. Fathers in the intellectual disability group were seen to be more depressed, had lower selfesteem and less satisfaction in their relationships with their children and wives than the other fathers and were described as having higher rates of neurotic tendencies; including a need for order and control. The results of this cross sectional study however, must be considered in the cultural and historical context of the time, and a slight decrease in paternal stress was seen where children were older, which may link with the earlier concept of adaptation over time. Houser and Seligman (1991) compared levels of stress and coping strategies used by 40 fathers of adolescents with intellectual disability aged between $12-19$ years and 31 fathers of typically developing adolescents. No significant 
difference between the two groups of fathers with regard to levels of stress was revealed, although fathers in the intellectual disability group used coping strategies in a different way to the other fathers, as discussed later. Rodrigue et al (1992) also carried out a comparative study on the family, socialecological and intrapersonal aspects of psychosocial functioning of 20 fathers of children who had autism, 20 fathers of children with Down syndrome and 20 of children who were typically developing. Similarity between the groups in terms of stress, marital satisfaction, social support, perceived parenting competence, parenting satisfaction and efficacy were found. The context of this study incorporates a US sample of predominantly white middle class fathers, who were members of a parent group and the children in the developmental disability group were significantly older than children in the typically developing group, both of which could influence the results.

A more recent US article by Boyraz and Sayger (2011) examined the role of family cohesion, adaptability, and paternal self-efficacy of 60 fathers of children with intellectual disability and 215 fathers of typically developing children. Analysis of various scales demonstrated that fathers of children who have a disability scored significantly higher than the other fathers on the self-acceptance dimension of psychological well-being and there was no difference between the two groups regarding family cohesion, adaptability and paternal self-efficacy. In contrast, an Irish study by MacDonald, Hastings and Fitzsimons (2010) based on 99 fathers of children diagnosed with intellectual disability aged between 6 18 , found that child behavioural issues were a significant predictor of paternal stress and depression.

For some fathers, the negative impact of their situation continues as their child grows. Hornby`s (1992) account of fathers' experiences of parenting a child with disabilities refers to the negative impact of sleeplessness, stress, feelings of anger towards the child, shame, guilt and even fantasising about the child's death. Despite this, there are also reports of fathers experiencing pleasure over small achievements, of love for their child and enjoyment from the relationship. The development of positive 
attributes over time are also noted, such as understanding, tolerance and appreciation (Baumann and Braddick 1999) whilst the evaluation of a programme for fathers of young children who have developmental disability undertaken by Vadasay et al (1985) refers to the opportunity to gain new information, new skills and advanced problem solving. This study also found that fathers who had taken part in the programme between one to three years demonstrated lower levels of depression, stress, sadness and guilt. It also found the fathers had higher levels of satisfaction in their interaction with others, increased levels of self-perceived success and self-expression than fathers who had only recently joined the programme; the findings could indicate positive adaptation over time.

\section{Concern for the future}

An associated stress highlighted in the literature was paternal concern for the future. According to West (1998) the future was a topic of discussion amongst fathers of children who had Down syndrome and Baumann and Braddick (1999) report specific concerns regarding the long-term welfare of the child and future accommodation needs. Concern about suitable longer-term care was also an emergent theme within studies by Hornby (1992) and Rivard, and Mastel-Smith (2014). Hornby (1995a) claims that in addition to long-term support needs fathers were concerned about support for the child after leaving the educational system, coping with adolescence, sexuality and the time when parents are no longer available to provide support. Vadasay et al (1986) confirmed these concerns but also highlight worry in respect of health, local services and increased pessimism about the future, despite a significant reduction in paternal levels of depression in their follow up evaluation of a fathers programme. A further dimension of concern is the financial impact of raising a disabled child in relation to current and future needs as noted by Rodrigue et al (1992); however this could be linked to the contextual setting of a US system.

\section{Work}


Research indicates that fathers want to care for their families, which raises work related issues (Carpenter and Towers 2008). Three aspects of work arise from the literature; that the child with an intellectual disability has an impact upon work; that work has an impact upon a father's care role and that work can offer functions other than a provider role for the father. Carpenter and Towers (2008) report upon the impact of a disabled child upon a father's employment and refer to reduced earnings and loss of opportunity. According to Ly and Goldberg (2014) who reported results related to the employment of 101 fathers of children with predominantly autistic spectrum disorder, some men perceived themselves to be in a secondary position at work on account of their domestic situation. The workplace may additionally restrict men's ability to attend meetings about their child and Carpenter and Towers (2008) claim this is particularly pertinent for men in less skilled and lower paid jobs. Ly and Goldberg (2014) and Rivard and Mastel-Smith (2014) also claim that work demands meant that fathers had difficulty in attending meetings as does Markowitz (1989) in a US study designed to explore the successes and failures of father participation in early childhood special education programmes. With regard to a care role and work, an investigation by MacDonald and Hastings (2010) into parental involvement of 105 fathers of children with an intellectual disability aged between 6 and 18 years, reports that fathers who work are less likely to be involved with care giving tasks.

Hornby (1995b) reported that stress levels of fathers of children with Down syndrome were higher where men were unemployed and lower when employed, which could suggest that work serves to reduce stress in some instances. This concept is supported by Bray et al (1995) who found that some fathers used work as a coping strategy to manage the stress of their situation, particularly after initial diagnosis, and by Herbert and Carpenter (1994) who found that some fathers use work as an attempt to return to "normality" after diagnosis. Work may therefore perform a particular function for fathers in that although it generates difficulties, it can be used by some as a coping strategy. 


\section{Roles and relationships:}

That mothers predominantly have the main care role is apparent within the literature. Baumann and Braddick (1999) claim that fathers worry about their child and want the best for them, yet in their sample of 11 fathers, only one took the main carer role, although this demonstrates that in some families, fathers can and do take on such a role. MacDonald and Hastings (2010) also found some fathers were very involved in the daily care of their child, particularly when the fathers did not work outside the home and the child was younger. Carpenter and Towers (2008) describe a range of paternal roles and engagement. Most fathers in this study referred to daily engagement and three participants reported themselves to be the main carer. Additional roles portrayed by fathers in this study were the provision of a support role to their partners and other children, providing care in the home and advocacy and resource finder roles, which were also reported by Bray et al (1995) who add that fathers want to provide a stable and caring environment for all their children.

A number of articles demonstrate similarities in the roles and relationships between fathers of children who have a disability and those who do not. Dyer et al (2009) conducted a longitudinal US study to consider fathers' involvement with their children over time. 450 fathers of children with a diagnosed disability or developmental delay and 3,100 fathers of children who were typically developing completed scales to examine functional involvement in literacy or language development at three stages. Results found more similarities in levels of involvement than differences between the fathers, however fathers of children diagnosed with disability at 9 months had highest baseline involvement but greatest decline in involvement over time. Young et al (1994) examined fathers' involvement in childcare, support, marital stress levels and functional style in 23 two-parent US families with a preschool-age child with disabilities and 24 families with a typically developing child. Again, there was no significant difference between the two groups of fathers related to paternal involvement, functional 
style within the family or marital stress, nor were there significant differences in paternal involvement as a result of the child's disability. This similarity in levels of involvement is reinforced by Ricci and Hodapp (2003) who compared fathers of children with Down syndrome versus other types of intellectual disability by using questionnaires and found that child rearing involvement was similar among the 30 fathers of children with Down syndrome and 20 fathers of children with other types of intellectual disability.

The research that provides a focus on the social and marital relationships however is inconsistent. Some research presents variability, some finds no significant difference whilst other studies present a positive impact. Cummings (1976) reported that fathers of children with intellectual disability, when compared with fathers of children with physical disability or those who were typically developing, experienced less satisfaction in their relationships with their children and wives. In contrast, Baumann and Braddick (1999) report variation as some men in their study claimed that they were now too busy to socialise, others made reference to support from family or friends and some reported a positive change in the marital relationship. Diversity was also noted by Bray et al (1995) as reduced social networks were reported by some fathers yet others commented upon strong support from family and friends although overall, fathers placed less importance on casual relationships. In reference to their marriage, some men in this study referred to marital disharmony but chose to remain in the marriage to provide support and stability to their family. Studies which present similarity in findings between fathers of children who have intellectual disability and those of children who are typically developing include Rodrigue et al (1992) and Young et al (1994). No significant difference between the groups of fathers in these studies was found in terms of marital satisfaction, and Rodrigue et al (1992) who compared fathers of children who had autism, Down syndrome and those who were typically developing, claimed that levels of social support, perceived parenting competence, parenting satisfaction and efficacy were similar between the 3 groups of fathers Hornby (1995b) also demonstrates no difference in levels of divorce, marital 
difficulties, depression or personality difficulties between fathers of children who have Down syndrome and the general population. Further studies have presented either no difference or improved marital satisfaction between different groups of fathers. Participants in the research by Rivard and Mastel-Smith (2014) reported no change or a closer relationship with wives on account of their child`s genetic disorder, whilst Hornby (1995a) claimed that most fathers of children with Down syndrome referred to a reported positive rather than negative impact upon their marriage. On a slightly different note, Herbert and Carpenter (1994) refer to an altered marital relationship in the presence of intellectual disability but associate this with service providers viewing the mother as the main carer and point of contact whilst resigning fathers to the role of secondary partner in the process.

\section{Impact of fathers upon child development}

Having considered the impact of the child with intellectual disabilities upon the father, the impact of the father upon the child is now presented. Diversity is again apparent with some research providing evidence of positive links and others presenting difficulty. De Falco et al (2008) video-recorded play sessions between 19 Italian fathers of young children who had Down syndrome to consider father-child interaction and play skills. This study indicated positive association between exploratory and symbolic play when the father was present compared to solitary play, and a greater use of symbolic play was apparent in the presence of high emotional availability between father and child. The result of this small scale study however could have been affected by the recording process and variables such as maternal situation and well-being, which were not considered. Elder et al (2005) also portray a positive association between father play and the development of pre-communication skills in children with a disability in their US study of 18 fathers from a range of ethnic backgrounds.

Two studies that present father impact upon child development in a less positive manner are those by Elder et al (2003) and Stevenson and Crnic (2013). The former compared and contrasted the findings of 
in-home training for 4 fathers of autistic children from different cultural backgrounds within the US. Although this study showed that fathers were able to learn the strategies of "imitation with animation" (imitating the child's behaviour in an exaggerated manner) and "expectant waiting" (promoting the child's behaviour and waiting for a positive response) to support communication, they were reportedly frustrated at not knowing how to play with their children, tended to direct the child`s play and demonstrated difficulty in the use of these strategies. Stevenson and Crnic (2013) examined the influence of paternal intrusive behaviour (defined as verbal and non-verbal behaviours that may restrict the child`s autonomy, ability to explore and develop self-regulation) upon the development of children's social skills and self-regulation. This research into 97 US families from a range of ethnic backgrounds found that such behaviour was a risk factor in the development of social skills in children who have developmental delay, all of which would suggest that the impact of fathers upon the developmental progress of their children may be positive or negative.

\section{Fathers and service providers}

The relationship between fathers and service providers within the research is again divergent. Carpenter and Towers (2008) report interaction with practitioners as a main theme and claim that one third of participants felt included by practitioners involved with their child, a further third felt that the focus was upon their wives and referred to a lack of information, whilst others referred to service providers feeling that it was not appropriate for fathers to provide a significant care role. Baumann and Braddick (1999) also present a range of interactions; some fathers felt grateful to specific institutions, yet metaphors of fighting to manage interactions with insurance companies, health care professionals and educational providers were used in other instances. The presence of diversity continues with Herbert and Carpenter (1994) who further report a range of styles from caring to non-caring when referring to fathers experience of service providers. 
The view that service providers consider fathers to be secondary to mothers in the care role is noted by Ly and Goldberg (2014) who found that services would direct their involvement towards mothers and the mother-child relationship, rather than the father-child relationship. Rivard and Mastel-Smith (2014) similarly raise the theme that fathers feel ignored by health care professionals and add the criticism that at the point of initial diagnosis, health care professionals lacked knowledge particularly where the condition was rare. Hornby (1992) adds to claims that fathers have negative feelings about professionals and report experiences of professional insensitivity, ignorance and the withholding of information.

Bray et al (1995) and Markowitz (1989) refer to the relationship between fathers and educationalists. According to Bray et al (1995), fathers reported frustration and anger at the educational system within a New Zealand context. Markowitz (1989) however provides a service provider perspective upon fathers of children who attended an early childhood special education programme across the USA. This study reports that one third of educational providers felt that working with fathers was often a challenge, that fathers were not always actively engaged at events, were less sharing of information, experience or feelings than mothers, and several programmes reduced father focused sessions due to poor attendance. However, it was also noted that some staff did not want to work weekends when many fathers would have been more likely to have been able to attend. Despite these reports of friction however, some fathers do work co-operatively with service providers as evidenced in programmes that have enhanced the development of their children with disabilities (Elder et al 2005; Vadasy et al 1985 and 1986).

\section{Father's needs and coping strategies}

The issue of father's needs and the use of coping strategies is raised within some studies. Carpenter and Towers (2008) report that half the fathers in their study claimed that their needs had never been considered nor support offered, whilst Herbert and Carpenter (1994) found that fathers tended to 
negate their own needs and focus rather on those of their child. This suggests fathers may have unmet needs.

That fathers seek out information is a common theme in the literature and could be described as both a need and a coping strategy. Gathering information on their child`s condition is present in studies by Bostrom and Bromberg (2014), Bray et al (1995) and Rivard and Mastel-Smith (2014) and according to Baumann and Braddick (1999), fathers want to understand why the disability had arisen and to improve the situation. Rivard and Mastel-Smith (2014) refer to fathers using internet databases and websites at initial diagnosis but then refer to information gathering via health care professionals, support groups and forums, and associate the acquisition of knowledge with a sense of empowerment.

The provision of appropriate information is therefore likely to be a core need which may be met by programmes aimed at fathers of children who have an intellectual disability. Vadasy et al (1985) report on a programme to support the needs of fathers of young children who have a disability. Their usual programme format included opportunities for fathers to learn skills in relation to their child's needs, gain information on conditions, opportunity to share concerns with other fathers and listen to invited guest speakers. Markowitz (1989) also makes suggestions in relation to service provision for fathers of children who have an intellectual disability and advises that men are more likely to engage with programmes related to the development of their child if they are made to feel welcome, if they are considered to have a valuable role and their work schedules are accommodated. Other suggestions to meet the needs of fathers included father-friendly resources and information, the opportunity for contact with other men (both male service providers and others fathers) and to be involved in the planning and evaluation of such sessions. With regard to engagement in therapy or education meetings, Ly and Goldberg (2014) similarly present the view that fathers need to be considered as having equal importance to mothers to avoid exclusion, a phenomena also noted by West (1998) and Herbert and 
Carpenter (1994). It is clear that work issues cause difficulty for fathers in the attendance at meetings and other service provision centered upon their child, therefore timing must be considered by service providers in order to facilitate father's engagement (Ly and Goldberg 2014; Herbert and Carpenter 1994).

In addition to needs for information and support, fathers in this situation have been described as utilising coping strategies. Rodrigue et al (1992) found that fathers of developmentally disabled children made more use of information seeking in relation to the care and support of their child than fathers of typically developing children, which could be considered an adaptive and appropriate response that is likely to result in increased knowledge. Other coping strategies are reported by Houser and Seligman (1991) in their comparative study of stress levels and coping used by fathers of adolescents with and without intellectual disability. Here, strategies such as distancing, positive reappraisal and escape avoidance were present in the disability group, whilst Bray et al (1995) reported the use of coping strategies such as alcohol, emotional withdrawal and escape into work. The inference was however, that such strategies may be used on a short or long term basis dependent upon the individual father, yet suggest that fathers may have unmet needs for advice and information on strategies that could help in the positive adaptation to their situation.

\section{Discussion:}

This review of the literature relates to fathers of people aged between 0-22 who have an intellectual disability. It is acknowledged that the findings of this review could be compared and contrasted to other related studies, for example mothers of people who have an intellectual disability. These studies may indicate differences between fathers and mothers, such as in levels of stress and coping mechanisms (Little 2002) or the enhanced benefit to mothers when fathers take part in intervention programmes for children with intellectual disability and behavioural management issues (May et al 2013). However, the 
remit of this literature review was to focus upon fathers on account of their limited presentation within empirical study and to do justice to the topic such comparison between fathers and mothers would need to be presented as a separate literature review.

The findings presented within this review demonstrate areas of commonality and difference. In terms of similarity in research findings, the responses to the initial diagnosis of intellectual disability, such as shock, distress and altered dreams, are commonly reported by fathers and this is apparent in both small scale studies (Hornby 1992; Baumann and Braddick 1999; Rivard and Mastel-Smith 2013; West 1998 and Herbert and Carpenter 1994), and larger studies (Hornby 1995a; Bostrom and Broberg 2014). Despite this initial distress however, many papers refer to paternal adjustment over time (Hornby 1992; Bostrom and Broberg 2014; Rivard and Mastel-Smith 2013; Baumann and Braddick 1999; Vadasay et al 1986; Hornby 1995a and Bray et al 1995; Quinn 1999; Davis and May 1991)

Further areas of similarity in research findings include paternal concern for the future in relation to care needs, accommodation, financial security, and what will happen when their child leaves the educational system (Baumann and Braddick 1999; Hornby 1992; Rivard and Mastel-Smith 2014; Hornby 1995a; Vadasay et al 1986 and Rodrigue et al 1992). Another similarity identified is that fathers seek out information as a coping strategy to better understand and support their child, (Bostrom and Bromberg 2014; Bray et al 1995; Rivard and Mastel-Smith 2014; Baumann and Braddick 1999; Rodrigue et al 1992 and Carpenter and Towers 2008), as is the concept that work is a barrier to being able to attend childrelated appointments (Carpenter and Towers 2008; Ly and Goldberg 2014; Rivard and Mastel-Smith 2014 and Markowitz 1989; Towers and Swift 2006; Towers 2009). In relation to roles and responsibilities while some men do take on the main caring role, it is often mothers who are the main carer, particularly when men work (Baumann and Braddick 1999; MacDonald and Hastings 2010; Carpenter and Towers 2008). Agreement across the research findings is also found regarding paternal roles and levels of 
engagement with child rearing and developmental activities, when comparing fathers of children with intellectual disability and those whose children are typically developing (Dyer, et al 2009; Rodrigue et al 1992; Young et al 1994; Ricci and Hodapp 2003).

The review found areas of disparity in the fathers' varied response to intellectual disability, in terms of paternal stress and wellbeing. Two studies report higher levels of paternal stress and dissatisfaction for fathers of children who have intellectual disability compared to other groups of fathers (Cummings 1976; Towers and Swift 2006), however, in contrast some report no differences between groups of fathers where disability was and was not present (Houser and Seligman 1991; Rodrigue et al 1992) and another reports higher levels of paternal psychological well-being in the intellectual disability group (Boyraz and Sayger 2011). The impact of intellectual disability upon roles and responsibilities, such as marriage and social relationships is also disputed as two studies note a range of social and marital relationships (Baumann and Braddick 1999; Bray et al 1995), while another reports less satisfaction (Cummings 1976). Others note similar levels of marital satisfaction or divorce rates between fathers in intellectual disability groups and those where children did not have disability (Rodrigue et al 1992, Young et al 1994; Hornby 1995b) and some studies note no difference or even improvement in the marital relationship (Rivard and Mastel-Smith 2014; Hornby 1995a).

The two other areas where there is a difference in the research findings are the impact of the father upon child development and father engagement with service providers. Positive association between father engagement in child development and skill acquisition was found by De Falco et al (2008) and Elder et al (2005), yet less positive results are noted elsewhere (Elder et al 2003; Stevenson and Crnic 2013). In reference to engagement with service providers, some fathers are presented as frustrated and angry with the educational system (Bray et al 1995) while others positively engaged in father specific programmes (Elder et al 2005; Vadasy et al 2005 and 2006). 
The findings of this review demonstrate areas of commonality and difference within the papers; these discrepancies may be due to a mixture of factors, such as data being collected at different stages, for example, fathers may be more likely to be reflective when their children are older, and also methodological differences because different data collection tools were used. However, the review indicates a clear need for further research, especially with the lack of research relating to fathers of adults aged 20 and above. With the expectation that parents, including fathers, will and do provide a long term support role over the life course (Emmerson and Hatton 2008) and the recognition that fathers may need assistance with such a role (Flippin and Crais 2011) the importance of considering fathers of adults with intellectual disability becomes evident.

Concern in relation to the demands of such a long term care role from parents has been raised at international and national level (Burke et al 2012; Taylor and Hodapp 2012). Nationally the demand upon parents is acknowledged at government level as demonstrated in papers such as 'Valuing people now: from progress to transformation' (Department of Health (DoH) 2008), 'Putting People First' (DoH 2008) and 'Family Matters' (DoH 2001), where the family need to access support for a care role is reiterated. Despite the call for support at a government level however, reviews of 'Valuing People' (DoH 2001) by Cooper and Ward (2011) and Mansell (2010) report that families who provide care for adults with multiple and profound disabilities note a lack of support outside the family, alongside poor access to and coordination of services, which creates additional pressure for families who provide support (Mclnnes et al 2011).

From this review of the literature, there are clear implications for service delivery and the education of those working in health, social care and educational contexts. Fathers want information that relates to their child (Rivard and Mastel-Smith 2014; Rodrigue et al 1992) and father specific events, regardless of service context, need to provide information on conditions, support the acquisition of skill development 
in relation to the child and offer the opportunity to share with other men (Vadasy et al 1985; Markowitz 1989). One example of this could be to provide information on the nature of autism spectrum disorder, followed by advice and techniques on how to understand and manage behavioural issues that may be associated with this condition. There is also a call for service providers in every context to both include and value fathers in all communication and aspects of service delivery, as it is suggested that fathers who feel undervalued and excluded, are less likely to engage with services (Markowitz 1989; Ly and Goldberg 2014; West 1998; Herbert and Carpenter 1994). Such a call therefore requires service providers to reconsider the view that the mother-child relationship has greater significance than the father-child relationship (Carpenter and Towers 2008; Ly and Goldberg 2014; Rivard and Mastel-Smith, 2014); recognising the father- child relationship may provide a different but equally valuable entity in the life of the child and family. A further need is for service providers to consider the timing of services to take into account possible work commitments, as this has been shown to create difficulties regarding father engagement with service providers (Ly and Goldberg 2014; Herbert and Carpenter 1994)and

finally, services need to consider the role and engagement of fathers across the life course of their child with intellectual disability due to changing social roles and expectations, budgetary constraints, service reduction and the longevity of people who have intellectual disability.

\section{Conclusion}

Although some studies have been completed on fathers of children who have an intellectual disability, there is a particular lack of research that involves fathers of adult children aged 20 and over. Studies that have been undertaken introduce the subject and raise important issues, however the research has not progressed to investigate the findings in any depth. This review presents areas of diversity and commonality within existing studies and draws attention to the need to value and support fathers in having a long term care role in the lives of their adult children with an intellectual disability, especially in 
the light of social expectation, increased longevity for all and a context of budgetary cuts and reduced service provision. The implications for service providers across the health, education and social care sectors have been set out alongside the call to give credence and value to the father-child relationship. Service design and provision needs to facilitate father engagement by considering practical elements, such as the timing of service delivery, and father specific needs for information and child related skills. The active engagement of fathers in service design, delivery and evaluation would further support fathers of children who have an intellectual disability in their role over the duration of the life course.

\section{4 words without references}

\section{Abstract 149 words}

\section{3 words when abstract included}

\section{References}

Baumann, S., L., \& Braddick, M. (1999) Out of Their Element: Fathers of Children Who Are "Not the Same". Journal of Pediatric Nursing, 14(6): 369-378.

Bertelli, M., Bianco, A., Rossi, M., Scuticchio, D., \& Brown, I. (2011). Relationship between individual quality of life and family quality of life for people with intellectual disability living in Italy. Journal of Intellectual Disability Research, 55(12):1136-50.

Bostrom, P., K., \& Broberg, M. (2014) Openness and avoidance - a longitudinal study of fathers of children with intellectual disability. Journal of Intellectual Disability Research, 58(9):810-821. 
Boyraz, G., \& Sayger, T., V. (2011) Psychological Well-Being Among Fathers of Children With and Without Disabilities: The Role of Family Cohesion, Adaptability and Paternal Self-Efficacy. American Journal of Men's Health, 5(4): 286-96.

Bray, A., Shelton, E., J., Ballard, K., \& Clarkson, J. (1995) Fathers of Children with Disabilities: some Experiences and Reflections. New Zealand Journal of Disability Studies, 1:164-176.

Burke, M. M., Taylor, J. L., Urbano, R., and Hodapp, R. M. (2012). Predictors of Future Caregiving by Adult Siblings of Individuals With Intellectual and Developmental Disabilities. American Journal of Intellectual and Developmental Disabilities. 117(1), pp. 33-47.

Carpenter, B., \& Towers, C. (2008) Recognising fathers: the needs of fathers of children with disabilities. Support for Learning, 23(3):118-125.

Cooper, V. and Ward, C. (2011). Valuing People: family matters ten years on. Tizard Learning Disability Review. 16(2), pp. 44-48.

Cummings, S., T. (1976) The impact of the child`s deficiency on the father: a study of fathers of mentally retarded and chronically ill children. American Journal of Orthopsychiatry. 46(2): 246-255.

Davis, P., B., \& May, J., E. (1991) Involving Fathers in Early Intervention and Family Support Programs: Issues and Strategies. Children's Health Care, 20(2):87-92.

de Falco, S., Esposito, G., Venuti, P., \& Bornstein, M., H. (2008) Fathers' play with their Down Syndrome children. Journal of Intellectual Disability Research, 52(6): 490-502.

Department of Health (2001). Family matters: counting families in. London: DoH. 
Department of Health (2008a). Valuing people now: from progress to transformation. London: DoH.

Department of Health (2008b). Putting People First- the whole story. London: DoH.

Dyer, W., J., McBride, B., A., Milagros Santos, R., \& Jeans, L., M. (2009) A Longitudinal Examination of Father Involvement With Children With Developmental Delays: Does Timing of Diagnosis Matter? Journal of Early Intervention, 31(3): 265-281

Elder, J., H., Valcante, G., Won, D., \& Zylis, R. (2003) Effects of in-home training for culturally diverse fathers of children with autism. Issues in Mental health Nursing, 24:273-295.

Elder, J, H., Valcante, G., Yarandi, H., White, D., \& Elder, T., H. (2005) Evaluating In-Home Training for Fathers of Children With Autism Using Single-Subject Experimentation and Group Analysis Methods. Nursing Research, 54 (1): 22- 32.

Flippin, M., \& Crais, E., R. (2011) The Need for More Effective Father Involvement in Early Autism Intervention: A Systematic Review and Recommendations Journal of Early Intervention, 33(1): 24-50.

Gallagher, J., Cross, A., \& Scharfman, W. (1981) Parental adaptation to a young handicapped child: The fathers role. Journal of the Division for Early Childhood. 3 (1):3-14.

Gore, N. (2010) Support for fathers of learning disabled children. Community Care. 1809 (Nov): 24-25

Herbert, E., \& Carpenter, B. (1994) Fathers - The Secondary Partners: Professional Perceptions and Fathers' Reflections. Children and Society, 8 (1): 31-41.

Hornby (1992) A Review of Fathers Accounts of their Experiences of Parenting Children with Disabilities. Disability, Handicap and Society, 7(4):363-374. 
Hornby (1995a) Fathers' Views of the Effects on their Families of Children with Down Syndrome. Journal of Child and Family Studies, 4 (1):103-117.

Hornby, G. (1995b) Effects on Fathers of Children with Down Syndrome. Journal of Child and Family Studies, 4(2): 1062-1024.

Houser, R., \& Seligman, M. (1991) A Comparison of Stress and Coping by Fathers of Adolescents With Mental Retardation and Fathers of Adolescents Without Mental Retardation. Research in Developmental Disabilities, Vol.12:251-260.

Little, L. (2002) Differences in Stress and Coping for Mothers and Fathers of Children with Asperger`s Syndrome and Nonverbal Learning Disorders. Pediatric Nursing. 28(6): 565-570.

Ly, A., R., \& Goldberg, W., A. (2014) New measures of fathers of children with developmental challenges. Journal of Intellectual Disability Research, 58(5):471-484.

MacDonald, E., E., Hastings, R., P., \& Fitzsimons, E. (2010) Psychological Acceptance Mediates the Impact of the Behaviour Problems of Children with intellectual Disability on Fathers' Psychological Adjustment. Journal of Applied Research in Intellectual Disabilities, 23: 27-27.

MacDonald, E., E., \& Hastings, R., P. (2010) Mindful Parenting and Care Involvement of Fathers of Children with Intellectual Disabilities. Journal of Child Family Studies, 19: 236-240.

Mansell, J. (2010). Raising our sights: Services for adults with profound intellectual and multiple disabilities. Tizard Learning Disability Review. 15(3), pp. 5-12.

Markowitz, J. (1989) Participation of Fathers in Early Childhood Special Education Programs: An Exploratory Study. Journal of the Division for Early Childhood, 8: 119-131. 
May, F.S., McLean, L.A., Anderson, A., Hudson, A., Cameron, C. \& Mathews, J. (2013) Father participation with mothers in the Signposts program: An initial investigation. Journal of Intellectual \& Developmental Disability. 38(1): 39-47.

Meyer, D., J., Vadasy, P., F., Fewell, R., R., \& Schell, G. (1982) Involving Fathers of Handicapped Infants: Translating Research into Program Goals. Journal of the Division for Early Childhood, 10 (1):64-72.

McInnes, E., E., Hills, A., \& Chapman, M., J. (2011). Eligibility for statutory learning disability services in the north-west of England. Right or luxury? Findings from a pilot study. British Journal of Learning Disabilities, 40(3):117-186.

O`Brien, M (2005) Shared Caring: Bringing fathers into the frame. Equal Opportunities Commission Working Paper Series number 18.Equal Opportunities Commission .Retrieved from http://core.ac.uk/download/pdf/4155069.pdf

Quinn, P. (1999) Supporting and encouraging father involvement in families of children who have a disability. Child and Adolescent Social Work, Vol 16 (6) 439-454

Rendall, D. (1997) Fatherhood and learning disabilities: a personal account of reaction and resolution. Journal of Learning Disabilities for Nursing, Health and Social Care, 1(2): 77-83.

Ricci, L., A., \& Hodapp, R., M. (2003) Fathers of children with Down's syndrome versus other types of intellectual disability: perceptions, stress and involvement. Journal of Intellectual Disability Research, 47(4/5):273-284.

Rivard, M., T., \& Mastel- Smith, B. (2014) The Lived Experience of Fathers Whose Children Are Diagnosed With a Genetic Disorder. Journal of Obstetric, Gynecologic, and Neonatal Nursing, 42: 38-49. 
Rodrigue, J., R., Morgan, S., B., \& Geffken, G., R. (1992) Psychosocial Adaptation of Fathers of Children with Autism, Down Syndrome, and Normal Development. Journal of Autism and Developmental Disorders, 22(2):249-263.

Stevenson, M., \& Crnic, K. (2013) Intrusive fathering, children's self-regulation and social skills: a mediation analysis. Journal of Intellectual Disability Research, 57(6):500-512.

Taylor, J. L., \& Hodapp, R. M. (2012). Doing nothing: adults with disabilities with no daily activities and their siblings. American Journal on Intellectual Developmental Disabilities, 117(1), pp. 67-79.

Towers, C. (2007) Let`s not forget about fathers. Learning Disability Today, 7 (2):15-21.

Towers, C. (2009) Recognising Fathers: A national survey of fathers who have children with learning disabilities. Foundation for People with Learning Disabilities; Mental Health Foundation. Retrieved from http://www.learningdisabilities.org.uk/content/assets/pdf/publications/recognising_fathers_survey.pdf ?view=Standard

Towers, C., \& Swift, P. (2006) Recognising Fathers - Understanding the issues faced by fathers of children with a learning disability. Foundation for People with Learning Disabilities; Mental Health Foundation.

Retrieved from http://www.learningdisabilities.org.uk/content/assets/pdf/publications/recognising_fathers_report.pdf ?view=Standard

Vadasy, P., F., Fewell, R., R., Meyer, D., J., \& Greenberg, M., T. (1985) Supporting Fathers of handicapped Young Children: preliminary Findings of Program Effects. Analysis and Intervention in Developmental Disabilities, 5:151-163. 
Vadasy, P., F., Fewell, R., R., Greenberg, M., T., Dermond, N., L., \& Meyer, D., J. (1986) Follow-up Evaluation of the Effects of Involvement in the Fathers Program. Topics in Early Childhood Special Education, 6 (2): 16-31.

West, A. (1998) The piloting of a group for the fathers of children with Down syndrome. Child: Care, Health and Development, 24(4):289-294.

West, S. (2000) Just a Shadow: A review of support to fathers of children with disabilities. Birmingham: Handsel Trust.

Young, D., M., \& Rooparine, J., L. (1994) Fathers' Childcare Involvement with Children With and Without Disabilities. Topics in Early Childhood Special Education, 14(4): 488-502. 